\title{
Thermotropic Liquid-Crystalline Copoly(ester amide) Containing a Flexible Spacer in the Main Chain
}

\author{
Toshiyuki URYU, * Jin Cherl Song, and Takashi Kato \\ Institute of Industrial Science, University of Tokyo, \\ Roppongi, Minato-ku, Tokyo 106, Japan
}

(Received September 8, 1988)

\begin{abstract}
Thermotropic behavior was observed in a number of aromatic copoly(ester amides) containing a flexible spacer based on 4,4'-dicarboxyl-1,10-diphenoxydecane, di-acetylated $p$-aminophenol and di-acetylated hydroquinone with or without di-acetylated aromatic diamine. The copoly(ester amide) was synthesized by melt polycondensation accompanied by the removal of acetic acid. The introduction of up to $50 \mathrm{~mol} \%$ of $p$-aminophenol units, i.e., $25 \mathrm{~mol} \%$ of the amide group, gave thermotropic liquid crystalline copoly(ester amide), though the thermotropic behavior disappeared at a greater concentration of $p$-aminophenyl units. A thermotropic copoly(ester amide) was prepared with $p$-phenylenediamine, 4,4'-diaminodiphenylmethane or 4,4'-diamino-3,3'dimethoxylbiphenyl as an amino group-containing monomer when it was used together with $p$ aminophenol as an essential amino-monomer. In the last case, up to $60 \mathrm{~mol} \%$ of amide groups was allowed to afford thermotropic liquid crystallinity. The polymer structure and thermotropic nature were examined by solid-state and solution ${ }^{13} \mathrm{C}$ NMR spectroscopy, differential scanning calorimetry, polarizing microscopy, and IR spectroscopy.

KEY WORDS Copoly(ester amide) / Melt Polycondensation / Thermotropic Liquid Crystallinity / Amide Group / Solid-State ${ }^{13} \mathrm{C}$ NMR / Solution ${ }^{13}$ C NMR / Differential Scanning Calorimetry / Mesophase Range / Nematic Threaded-Schlieren Texture / Droplets Texture /
\end{abstract}

Aromatic polyamides and polyesters have opened a new field of liquid-crystalline polymers with high strength and high modulus. ${ }^{1-3}$ In general, aromatic polyamides are of lyotropic liquid crystalline, whereas aromatic polyesters are of thermotropic nature. Thermotropic polyamides ${ }_{2} \mathrm{COC}_{6} \mathrm{H}_{4} \mathrm{O}\left(\mathrm{CH}_{2}\right)_{10} \mathrm{O}$ $\mathrm{C}_{6} \mathrm{H}_{4} \mathrm{CONHC} \mathrm{H}_{6} \mathrm{H}_{3}(\mathrm{X}) \mathrm{C}_{6} \mathrm{H}_{3}(\mathrm{X}) \mathrm{NH}$, prepared by polymerization of $4,4^{\prime}$-dichloroformyl-1,10diphenoxydecane and 3,3'-disubstituted-4,4'diaminobiphenyl, have been reported. ${ }^{4}$ Strictly speaking, these are poly(ether amides), though di-alkoxy portions in the poly(ether amides) are regarded as spacers to reduce transition temperatures. Synthesis of thermotropic liquid crystalline samples of wholly aromatic copoly(ester amides), in which $p$-aminophenol was used as an amino-containing component

\footnotetext{
* To whom correspondence should be addressed.
}

has been reported. ${ }^{5,6}$ In the copoly(ester amide), however, the percentage of amide linkages included in all polymeric linkages was not so high. Recently, the synthesis of aliphatic-aromatic poly(ester amide) with thermotropic liquid crystalline character was reported. $^{?}$

Lenz and coworkers have synthesized various thermotropic polyesters with flexible spacers to lower the melting point. ${ }^{8}$ Recently, we reported that solid-state ${ }^{13} \mathrm{C}$ NMR spectra of thermotropic polyesters with di-alkoxy spacers can provide exact information on their solid structures. ${ }^{9}$

If di-alkoxy spacers are introduced in polymer backbone to lower the melting point and the liquid crystalinity measurement is carried out by use of both conventional polarizing 
microscopy and solid-state ${ }^{13} \mathrm{C}$ NMR spectroscopy, it might be easy to synthesize and characterize thermotropic copoly(ester amide).

In the present work, we synthesized thermotropic copoly(ester amide) containing up to $25 \mathrm{~mol}^{\%} \%$ of amide linkages, which are introduced by polycondensing di-acetylated $p$ aminophenol or di-acetylated $p$-aminophenol and di-acetylated $p$-substituted aromatic diamine in combination as amide-forming components, and 1,10-dioxydecamethylene as a flexible spacer.

\section{EXPERIMENTAL}

\section{4,4'-Dicarboxy-1,10-diphenoxydecane (1)}

1 was obtained by alkaline hydrolysis of 4,4'-dicarbethoxy-1,10-diphenoxydecane (2). 2 was prepared according to the Griffin and Havens' method. ${ }^{10}$ In a 11 three- necked flask, p-hydroxybenzoic acid ethyl ester (Tokyo Kasei Co.) $(33.2 \mathrm{~g}, 0.20 \mathrm{~mol})$ was dissolved in $25 \mathrm{ml}$ of dimethylformamide (DMF) under nitrogen atmosphere. Anhydrous sodium carbonate

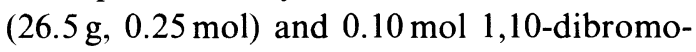
decane were added to the reaction flask, followed by the addition of $25 \mathrm{ml}$ of DMF. The mixture was heated for $6 \mathrm{~h}$ in an oil bath maintained at $140^{\circ} \mathrm{C}$ and refluxed with continuous stirring. It was allowed to cool to approximately $50^{\circ} \mathrm{C}$ and then poured into 51 of cold water. The solution containing the precipitated solid was kept overnight in a refrigerator. The precipitate was washed three times with water, and was filtered. Thereafter, it was recrystallized from $95 \%$ ethanol and finally dried under vacuum at $60^{\circ} \mathrm{C}$ for $48 \mathrm{~h}$. The yield of 2 was $28.5 \mathrm{~g}(61 \%) . \mathrm{mp} 105^{\circ} \mathrm{C}$ (lit. $\left.{ }^{11} 108.5-110^{\circ} \mathrm{C}\right) .2(23.5 \mathrm{~g}, 0.05 \mathrm{~mol})$ was added to $500 \mathrm{ml}$ of a $10 \%(\mathrm{w} / \mathrm{v})$ solution of potassium hydroxide in $95 \%$ ethanol. The resulting suspension was stirred under reflux for $6 \mathrm{~h}$. It was then diluted with 51 water and warmed to $60^{\circ} \mathrm{C}$, thoroughly dissolving the potassium salt of 4,4'-dicarboxy-1,10-diphenoxydecane. Concentrated hydrochloric acid was added to the warm solution until it was acidic to $\mathrm{pH}$ test paper. After the solution was allowed to cool overnight, the deposit crude 1 was filtered and washed with water. It was purified by recrystallization from a DMF$95 \%$ ethanol mixture. Yield, $14.3 \mathrm{~g}(69 \%) \mathrm{mp}$ $277^{\circ} \mathrm{C}$ (lit. ${ }^{11} 273-274^{\circ} \mathrm{C}$ ).

\section{Di-Acetylated p-Aminophenol and Aromatic Diamines}

Commercial $p$-aminophenol (Tokyo Kasei Co.) $\mathrm{mp}\left(155^{\circ} \mathrm{C}\right)$ and $p$-phenylenediamine (Tokyo Kasei Co.) (mp $305^{\circ} \mathrm{C}$ ) were used without further purification. 4,4'-Diaminodiphenylmethane $(25 \mathrm{~g})$ was acetylated with $50 \mathrm{ml}$ of acetic anhydride and $45 \mathrm{ml}$ of pyridine for $12 \mathrm{~h}$ at room temperature. Yield of $4,4^{\prime}$-diacetamidodiphenylmethane was $34.4 \mathrm{~g}$ $\left(97 \%\right.$ ). mp $233^{\circ} \mathrm{C}$ (lit. ${ }^{12} 236-237^{\circ} \mathrm{C}$ ). 4,4'Diamino-3,3'-dimethoxybiphenyl $(5 \mathrm{~g})$ was acetylated in the same manner. The yield of 4,4'-diacetamido-3,3'-dimethoxybiphenyl was $4.3 \mathrm{~g}(64 \%)$. mp $242^{\circ} \mathrm{C}$ (lit. ${ }^{13} 242-243^{\circ} \mathrm{C}$ ).

\section{Polymerization}

1 ( 1 or 2 g scale), di-acetylated $p$-aminophenol, di-acetylated hydroquinone, and di-acetylated aromatic diamines were polymerized using $10 \mathrm{mg}$ of $\mathrm{Zn}\left(\mathrm{CH}_{3} \mathrm{CO}_{2}\right)_{2} 2 \mathrm{H}_{2} \mathrm{O}$ as a catalyst in the stream of nitrogen. As an example, the case of $10 \mathrm{P} 20 \mathrm{H}$ is described. $1\left(2 \mathrm{~g}, 4.83 \times 10^{-3}\right.$ $\mathrm{mol})$, di-acetylated $p$-aminophenol $(0.186 \mathrm{~g}$, $\left.9.7 \times 10^{-4} \mathrm{~mol}\right)$, di-acetylated hydroquinone $\left(0.750 \mathrm{~g}, 3.86 \times 10^{-3} \mathrm{~mol}\right)$, and zinc acetate $(10 \mathrm{mg})$ were heated in a glass polymerization tube successively at $100^{\circ} \mathrm{C}$ for $1 \mathrm{~h}$, at $150^{\circ} \mathrm{C}$ for $1 \mathrm{~h}$, and at $240^{\circ} \mathrm{C}$ for $1 \mathrm{~h}$, and then polymerized at $300^{\circ} \mathrm{C}$ for $5 \mathrm{~h}$ under the stream of nitrogen until evolution of acetic acid practically ceased. Thereafter, the polymerization was continued at $300^{\circ} \mathrm{C}$ for $2 \mathrm{~h}$ under vacuum. The lumpy polymer obtained was ground. Yield, $2.0 \mathrm{~g}(85 \%)$.

\section{Measurements}

Thermal properties of the polymers were 
measured using a Perkin-Elmer DSC-2 calorimeter. The heating and cooling rates were maintained at $20^{\circ} \mathrm{C} \min ^{-1}$. The peak top was taken as a phase transition temperature. The visual and photographic observations were carried out with a polarizing microscope equipped with a Mettler FP85 hot stage. Solidstate and solution ${ }^{13} \mathrm{C}$ NMR spectra were recorded using a JEOL GX270 spectrometer (6.34 Telsa, $67.8 \mathrm{MHz}$ frequency) with a CP/MAS unit. ${ }^{9}$ In the case of solid-state measurement, contact time was $2 \mathrm{~ms}$ and recycle time of pulse was $5 \mathrm{~s}$. A bullet-type Kel-F rotor contained approximately $300 \mathrm{mg}$ of sample. The solution spectrum was taken on a $1 \%$ polymer solution in a mixture of
$40 \% 1,1,2,2$-tetrachloroethane- $d_{2}\left(\right.$ TCE- $\left.d_{2}\right)$ and $60 \%$ pentafluorophenol (PFP) at $27^{\circ} \mathrm{C}$. The absorption of TCE- $d_{2}$ was used as an internal standard (74.5 ppm downfield from tetramethylsilane reference).

\section{RESULTS AND DISCUSSION}

Preparation of Thermotropic Aromatic Copoly(ester amide) with a Flexible Spacer

A copoly(ester amide) (3) was prepared by the melt polycondensation of 4,4'-dicarboxy1,10-diphenyldecane, di-acetylated $p$-aminophenol, and di-acetylated hydroquinone according to eq 1. 1,10-Dioxy-decamethylene was used as a flexible spacer group. The results
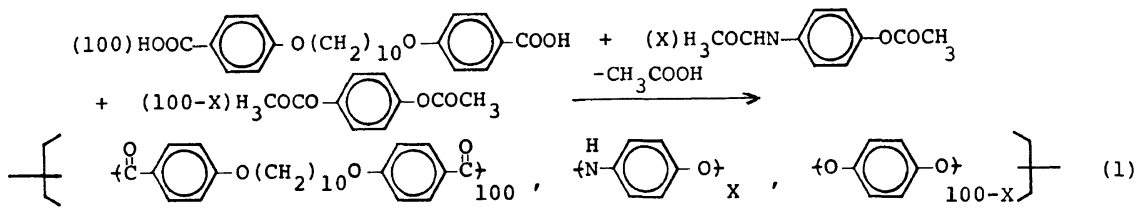

of polycondensations and thermal mesurements are shown in Table I. The yield was 82 $89 \%$, a loss is mostly due to loss of the polymer attached to the glass polymerization tube. Reduced viscosities of the polymers were in the range of $0.22-0.31 \mathrm{dl} \mathrm{g}^{-1}$.

A copoly(ester amide) containing $20 \% p$ -

aminophenol units; 10P20H, exhibited a nematic phase at $232^{\circ} \mathrm{C}\left(T_{\mathrm{m}}\right)$ and became isotropic at $324^{\circ} \mathrm{C}\left(T_{\mathrm{i}}\right)$.

A polyester with a similar structure, $10 \mathrm{HQ}$, showed lower $T_{\mathrm{m}}$ by $7^{\circ} \mathrm{C}$ and higher $T_{\mathrm{i}}$ by $2^{\circ} \mathrm{C}$ than respective transition temperatures of the copoly(ester amide). As the $p$-aminophenol

Table I. Thermal properties of thermotropic copoly(ester amide)s (3) ${ }^{\mathrm{a}}$

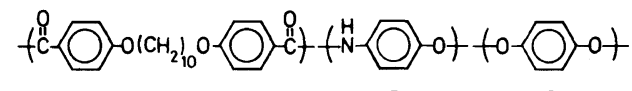

A

B C

\begin{tabular}{|c|c|c|c|c|c|c|c|c|}
\hline \multirow{2}{*}{ Polymer } & \multicolumn{3}{|c|}{ Molar ratio } & \multirow{2}{*}{$\frac{T_{\mathrm{m}}}{{ }^{\circ} \mathrm{C}}$} & \multirow{2}{*}{$\frac{T_{\mathrm{i}}}{{ }^{\circ} \mathrm{C}}$} & \multirow{2}{*}{$\frac{T_{\mathrm{i}}-T_{\mathrm{m}}{ }^{\mathrm{b}}}{{ }^{\circ} \mathrm{C}}$} & \multirow{2}{*}{$\frac{\text { Yield }}{\%}$} & \multirow{2}{*}{$\frac{\eta_{\text {red }}}{\mathrm{dl} \mathrm{g}^{-1}}$} \\
\hline & A & B & $\mathrm{C}$ & & & & & \\
\hline $10 \mathrm{HQ}$ & 100 & & 100 & 225 & 326 & 101 & 82 & 0.59 \\
\hline $10 \mathrm{P} 20 \mathrm{H}$ & 100 & 20 & 80 & 232 & 324 & 92 & 85 & 0.25 \\
\hline $10 \mathrm{P} 30 \mathrm{H}$ & 100 & 30 & 70 & 234 & 317 & 83 & 86 & 0.22 \\
\hline $10 \mathrm{P} 40 \mathrm{H}$ & 100 & 40 & 60 & 244 & 309 & 65 & 85 & 0.22 \\
\hline $10 \mathrm{P} 50 \mathrm{H}$ & 100 & 50 & 50 & 244 & 290 & 46 & 86 & 0.23 \\
\hline $10 \mathrm{P} 60 \mathrm{H}$ & 100 & 60 & 40 & - & 248 & 0 & 89 & 0.31 \\
\hline
\end{tabular}

a Measured by DSC.

b $T_{\mathrm{i}}-T_{\mathrm{m}}$, mesophase temperature range. 
unit increased, $T_{\mathrm{m}}$ increased and $T_{\mathrm{i}}$ decreased. However, copoly(ester amide) containing more than $60 \%$ of $p$-aminophenol did not exhibited thermotropic liquid crystal behaviors. A poly(ester amide) containing 50 $\mathrm{mol} \%$ of amide groups, obtained from $p$ aminophenol and methoxy-p-phenylenedicarboxylic acid, has afforded anisotropic melt. ${ }^{5}$ In our study, the copoly(ester amide) containing a long di-alkoxy spacer showed thermotropic liquid crystal behavior in the case of low amide group content.

The mesophase temperature range was $92^{\circ} \mathrm{C}$ for $10 \mathrm{P} 20 \mathrm{H}$, and reduced with increasing amide groups to afford $46^{\circ} \mathrm{C}$ in a polymer containing $50 \%$ of aminophenol unit, $10 \mathrm{P} 50 \mathrm{H}$.

The synthesis of polyamides from $p$ phenylenediamine alone as an amide-forming component did not give thermotropic liquid crystalline polyamides. Thus, $p$-phenylenediamine was used together with $p$-aminophenol.

The results of copolymerizations consisting of four monomers, that is, 4,4'-dicarboxy1,10-diphenoxydecane, di-acetylated $p$ aminophenol, di-acetylated $p$-phenylenediamine and di-acetylated hydroquinone, are shown in Table II. A copoly(ester amide) 10PHD-1 containing $5 \mathrm{~mol} \%$ of $p$-aminophenol unit and $5 \mathrm{~mol} \%$ of $p$-phenylenediamine unit was thermotropic, indicating $T_{\mathrm{m}}$ of $196^{\circ} \mathrm{C}$ and $T_{\mathrm{i}}$ of $306^{\circ} \mathrm{C}$. In this copoly(ester amide) series, both $T_{\mathrm{m}}$ and $T_{\mathrm{i}}$ increas- ed with amide content, and the mesophase temperature range, $T_{\mathrm{i}}-T_{\mathrm{m}}$, decreased. Up to $15 \mathrm{~mol} \%$ of both $p$-aminophenol and $p$-phenylenediamine units, an amide content of up to $22.5 \mathrm{~mol} \%$ exhibited thermotropic liquid crystalline nature, while beyond this content a copoly(ester amide) 10PHD-4 did not show it.

The reason why the $p$-aminophenol units in these copoly(ester amides) help to form liquid crystalline phase might be due to a decrease in the symmetric nature of the polymer backbone, that is, asymmetry originates from different bonding orders of the aminophenol unit in the polymer backbone, $-\mathrm{NHC}_{6} \mathrm{H}_{4} \mathrm{CO}$ and $-\mathrm{OCC}_{6} \mathrm{H}_{4} \mathrm{NH}$-. It is assumed that this disorder might cause a decrease in hydrogen bonds between amide groups. It has been reported that a polyester with an alternating arrangement of mesogenic units did not show a mesophase. ${ }^{14}$

When di-acetylated 4,4'-diaminodiphenylmethane, which can not generate a thermotropic liquid crystalline copoly(ester amide) in a case of single use, was used as an amideforming component together with di-acetylated $p$-aminophenol, a thermotropic copoly(ester amide) was obtained (5). The results of copolymerizations consisting of four monomers are shown in Table III. Although introduction of $15 \mathrm{~mol} \%$ each of $p$-aminophenol and 4,4'-diaminodiphenylmethane led to thermotropic liquid crystallinity, no meso-

Table II. Thermal properties of thermotropic copoly(ester amide)s (4) ${ }^{\mathrm{a}}$

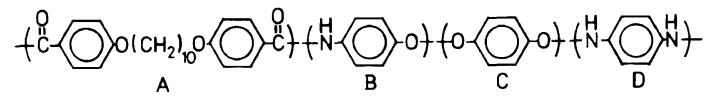

\begin{tabular}{|c|c|c|c|c|c|c|c|c|}
\hline \multirow{2}{*}{ Polymer } & \multicolumn{4}{|c|}{ Molar ratio } & \multirow{2}{*}{$\frac{T_{\mathrm{m}}}{{ }^{\circ} \mathrm{C}}$} & \multirow{2}{*}{$\frac{T_{\mathrm{i}}}{{ }^{\circ} \mathrm{C}}$} & \multirow{2}{*}{$\frac{T_{\mathrm{i}}-T_{\mathrm{m}}{ }^{\mathrm{b}}}{{ }^{\circ} \mathrm{C}}$} & \multirow{2}{*}{$\frac{\text { Yield }}{\%}$} \\
\hline & A & B & $\mathrm{C}$ & $\mathrm{D}$ & & & & \\
\hline 10PHD-1 & 100 & 5 & 90 & 5 & 196 & 306 & 110 & 91 \\
\hline 10PHD-2 & 100 & 10 & 80 & 10 & 233 & 308 & 75 & 89 \\
\hline 10PHD-3 & 100 & 15 & 70 & 15 & 260 & 323 & 63 & 92 \\
\hline 10PHD-4 & 100 & 20 & 60 & .20 & - & 298 & 0 & 91 \\
\hline
\end{tabular}

a Measured by DSC.

b $T_{\mathrm{i}}-T_{\mathrm{m}}$, Mesophase temperature range. 
Table III. Thermal properties of thermotropic copoly(ester amide)s (5) ${ }^{\mathrm{a}}$

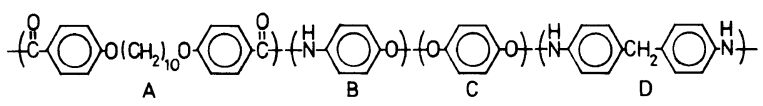

\begin{tabular}{|c|c|c|c|c|c|c|c|c|}
\hline \multirow{2}{*}{ Polymer } & \multicolumn{4}{|c|}{ Molar ratio } & \multirow{2}{*}{$\frac{T_{\mathrm{m}}}{{ }^{\circ} \mathrm{C}}$} & \multirow{2}{*}{$\frac{T_{\mathrm{i}}}{{ }^{\circ} \mathrm{C}}$} & \multirow{2}{*}{$\frac{T_{\mathrm{i}}-T_{\mathrm{m}}{ }^{\mathrm{b}}}{{ }^{\circ} \mathrm{C}}$} & \multirow{2}{*}{$\frac{\text { Yield }}{\%}$} \\
\hline & A & B & $\mathrm{C}$ & $\mathrm{D}$ & & & & \\
\hline 10РНMT-1 & 100 & 10 & 80 & 10 & 225 & 297 & 72 & 92 \\
\hline 10РНMT-2 & 100 & 15 & 70 & 15 & 180 & 250 & 70 & 92 \\
\hline 10РНMТ-3 & 100 & 20 & 60 & 20 & - & 270 & 0 & 92 \\
\hline
\end{tabular}

a Measured by DSC

b $T_{\mathrm{i}}-T_{\mathrm{m}}$, Mesophase temperature range.

Table IV. Thermal properties of thermotropic copoly(ester amide)s (6) ${ }^{\mathrm{a}}$

\begin{tabular}{|c|c|c|c|c|c|c|c|c|}
\hline \multirow{2}{*}{ Polymer } & \multicolumn{4}{|c|}{ Molar ratio } & $T_{\mathrm{m}}$ & $T_{\mathrm{i}}$ & $T_{\mathrm{i}}-T_{\mathrm{m}}^{\mathrm{b}}$ & Yield \\
\hline & A & B & $\mathrm{C}$ & $\mathrm{D}$ & ${ }^{\circ} \mathrm{C}$ & ${ }^{\circ} \mathrm{C}$ & ${ }^{\circ} \mathrm{C}$ & $\%$ \\
\hline 10PHMD-1 & 100 & 10 & 80 & 10 & 215 & 308 & 93 & 92 \\
\hline 10РНМТ-2 & 100 & 15 & 70 & 15 & 203 & 300 & 97 & 92 \\
\hline 10РНMT-3 & 100 & 20 & 60 & 20 & 193 & 295 & 100 & 92 \\
\hline 10РНMT-4 & 100 & 25 & 50 & 25 & 170 & 280 & 110 & 95 \\
\hline 10РНMT-5 & 100 & 30 & 40 & 30 & 160 & 273 & 118 & 95 \\
\hline 10РНМТ-6 & 100 & 35 & 30 & 35 & 155 & 277 & 122 & 98 \\
\hline 10РНМТ-7 & 100 & 40 & 20 & 40 & 145 & 270 & 125 & 94 \\
\hline
\end{tabular}

${ }^{a}$ Measured by DSC.

b $T_{\mathrm{i}}-T_{\mathrm{m}}$, Mesophase temperature range.

phase was observed with $20 \mathrm{~mol} \%$ each of in equimolar amounts of $10-40 \mathrm{~mol} \%$ as the two amines. amide-forming components according to eq

Diacetylated 4,4'-diamino-3,3'-dimethoxy- 2, giving thermotropic copoly(ester amide) biphenol and $p$-aminophenol were employed (6) (Table IV). In this case, the maximum

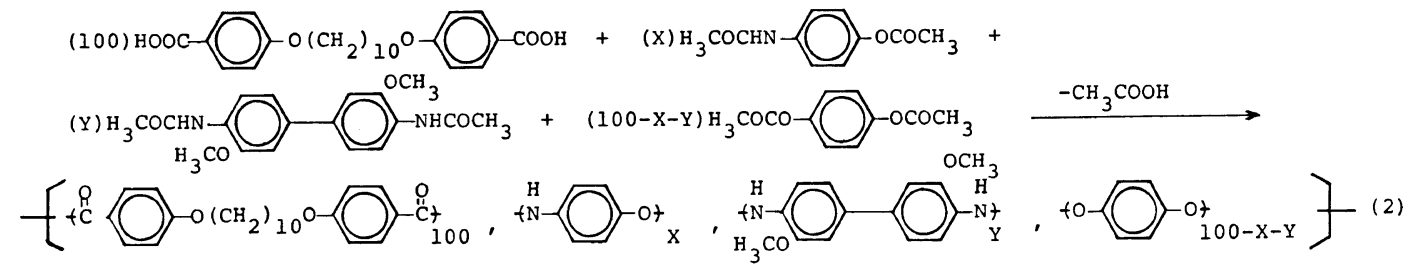

content of the amide groups was $60 \mathrm{~mol} \%$. In the case of $10 \mathrm{~mol}^{\circ} \%$ each of the two components, $T_{\mathrm{m}}$ and $T_{\mathrm{i}}$ were $215^{\circ} \mathrm{C}$ and $308^{\circ} \mathrm{C}$ respectively. Although both $T_{\mathrm{m}}$ and $T_{\mathrm{i}}$ decreased with an increase in the amide content, lowering in $T_{\mathrm{m}}$ was larger than $T_{\mathrm{i}}$. Thus, the 
mesophase temperature range expanded with amide content. The wide mesophase temperature range might be due to enlarged asymmetry caused by 3,3'-dimethoxy substituents in the 3,3'-disubstituted-4,4'-diaminobiphenyl unit. We assume that rotaton around the biphenyl C-C bond changes the geometrical position of the methoxy groups in the rod-like polymer chain, then fixing the following structural units (Figure 1).

Griffin and coworkers reported that a ther-

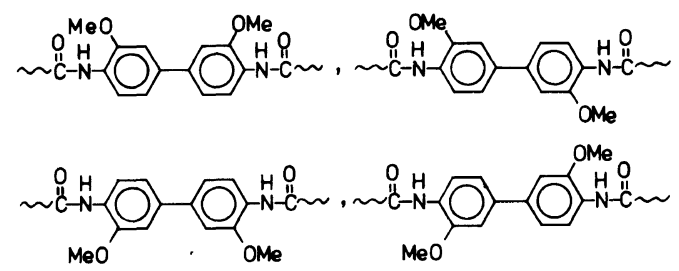

Figure 1. Probable conformational isomerism for $3,3^{\prime}$ dimethoxy-4,4'-diaminobiphenyl units. motropic polyamide was prepared by solution polymerization of $4,4^{\prime}$-dichloroformyl-1,10diphenoxydecane with 4,4'-diamino-3,3'-dimethoxybiphenyl. ${ }^{4}$ The polyamide showed $T_{\mathrm{m}}$ of $256^{\circ} \mathrm{C}$ and $T_{\mathrm{i}}$ of $276^{\circ} \mathrm{C}$, indicating that it has a high $T_{\mathrm{m}}$ and narrow mesophase range 20 degree. It is noteworthy that the copoly(ester amide) obtained in our study show a wide mesophase range.

\section{Solid-State CP/MAS ${ }^{13} C$ NMR Spectra of Copoly(ester amide)}

Solid-state CP/MAS ${ }^{13} \mathrm{C}$ NMR spectrum of the copoly(ester amide) $10 \mathrm{P} 20 \mathrm{H}$ was measured with a sideband-free pulse sequence, as shown in Figure 2.

In the solid-state spectrum, alkylene carbons in the di-alkoxy portion appear as sharp peaks at $27-70 \mathrm{ppm}$, in which $\mathrm{C}_{\gamma}$ is at $27.7 \mathrm{ppm}$, and $\mathrm{C}_{\beta}, \mathrm{C}_{\delta}$, and $\mathrm{C}_{\varepsilon}$ overlap at $32.5 \mathrm{ppm}$, and $\mathrm{C}_{\alpha}$

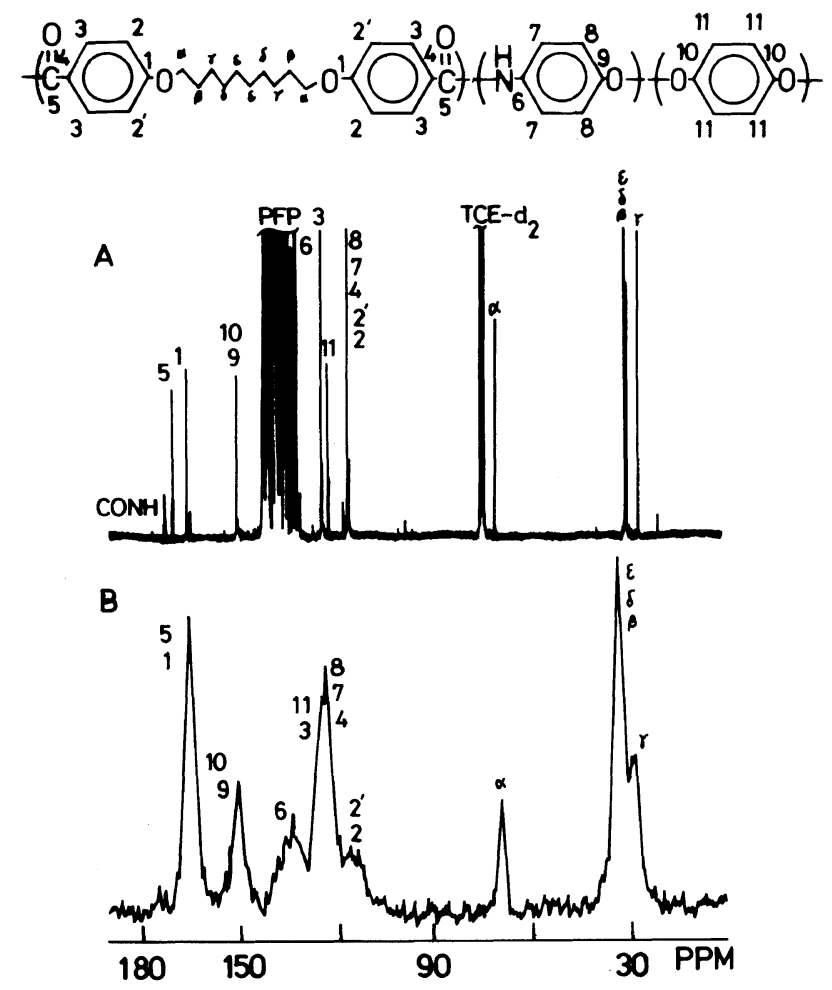

Figure 2. $67.8 \mathrm{MHz}^{13} \mathrm{C} \mathrm{NMR}$ spectra of $10 \mathrm{P} 20 \mathrm{H}$ : (A) solution spectrum obtained in TCE- $d_{2}$ and PFP; (B) solid-state spectrum which is free of spinning sidebands. 
neighboring to an oxygen appears at $68.5 \mathrm{ppm}$. Aromatic carbons arise at $110-170 \mathrm{ppm}$. The assignment of individual absorption was carried out by reference to the previous paper ${ }^{8}$ and the substitutent effect of the ${ }^{13} \mathrm{C}$ chemical shift. ${ }^{15}$

For poly ( $p$-phenylene terephthalamide), the nonequivalence of the four ortho carbons in the terephthalic moiety has been reported. ${ }^{16}$ In the previous paper, ${ }^{9}$ we observed the nonequivalence of ortho carbons to an alkoxy group in a thermotropic polyester having a hexamethylene spacer in the polymer backbone and concluded that it originated from all-trans conformation of the hexamethylene moiety. However, in Figure 2 for $10 \mathrm{P} 20 \mathrm{H}$, the 2 and $2^{\prime}$ carbon, i.e., ortho carbons, are not separated, being similr to the absorptions of the heat-treated thermotropic polyester prepared by low temperature solution polymerization and then heated at a high temperature. ${ }^{9}$ Since the poly(ester amide) were obtained by polycondensation at $300^{\circ} \mathrm{C}$, it is considered that the polymers have already been subjected to heat-treatment.

Although ester and amide carbon absorptions were separately observed at 168.7 and
$171.3 \mathrm{ppm}$ in the solution spectrum, respectively, they overlapped at $170 \mathrm{ppm}$ in the solidstate spectrum. IR spectra of $10 \mathrm{P} 20 \mathrm{H}$ and $10 \mathrm{P} 50 \mathrm{H}$ clearly indicated the existence of $\mathrm{CONH}$, with the $\mathrm{NH}$ and $\mathrm{CO}$ absorptions appearing around $3400 \mathrm{~cm}^{-1}$ and $1680 \mathrm{~cm}^{-1}$, respectively.

\section{Thermotropic Liquid-Crystal Phase}

All these polymers showed typical nematic textures by observation on a hot-stage of a polarizing microscope (Figures $3 \mathrm{~A}-\mathrm{C}$ ). A thermotropic polyester obtained with $4,4^{\prime}$ dichloroformyl-1,10-diphenoxydecane and hydroquinone has shown a nematic threadedSchlieren texture. ${ }^{17}$

A copoly(ester amide), 10P20H, which contained $20 \mathrm{~mol} \%$ of $p$-aminophenol, exhibited a texture similar to a threaded-Schlieren texture (Figure 3A). On the other hand, 10P50H showed a droplet texture when measured in the descending temperature cycle from an isotropic melt (Figure 3B).

It was revealed that copoly(ester amide) containing four components display textures slightly different from the three component copoly(ester amide). A copoly(ester amide),
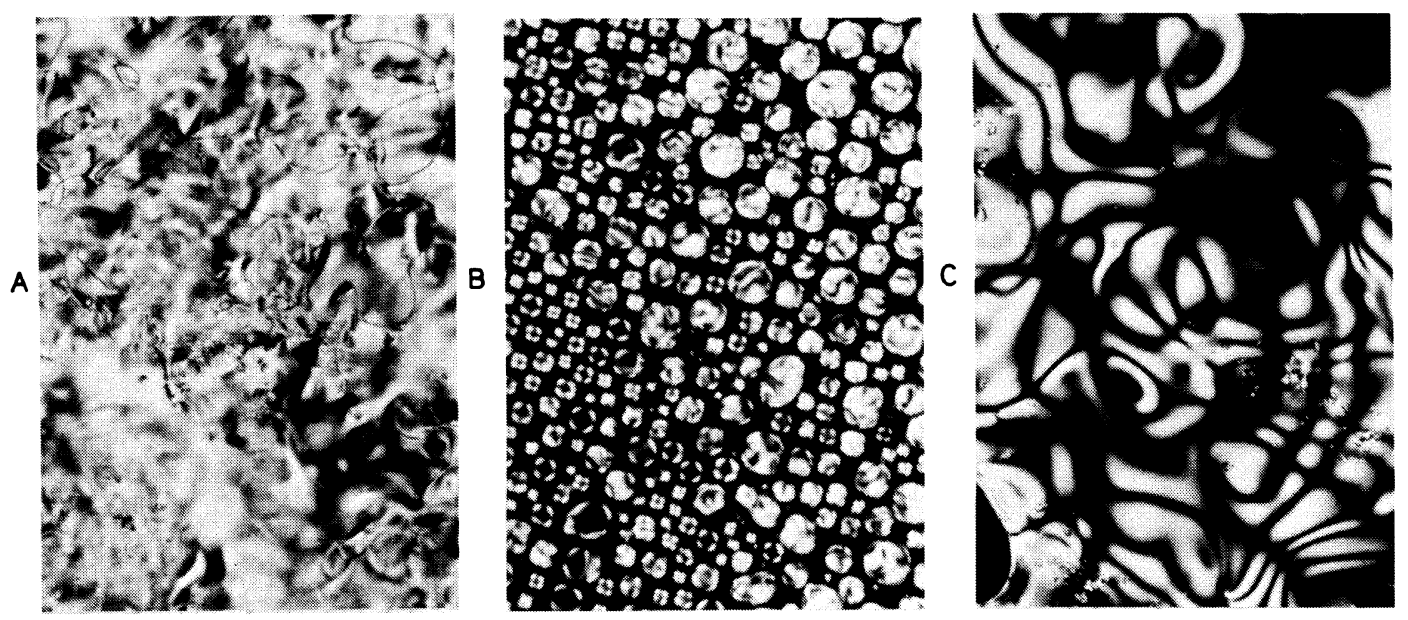

Figure 3. Photomicrographs of nematic phase from copoly(ester amide), (A) threaded texture of $10 \mathrm{P} 20 \mathrm{H}$, taken at $250^{\circ} \mathrm{C}$, (B) droplets texture of $10 \mathrm{P} 50 \mathrm{H}$, taken near $T_{\mathrm{i}},(\mathrm{C})$ Schlieren texture of 10PHD-2, at $250^{\circ} \mathrm{C}$ (magnification $\left.\times 150\right)$. 
10PHD-2, containing $10 \mathrm{~mol} \%$ of $p$-phenylenediamine unit showed a typical Schlieren texture having a brightly colored pattern in the limited range of $280-290^{\circ} \mathrm{C}$ (Figure 3C). Other thermotropic copoly(ester amide) displayed individual nematic textures depending on the composition and measuring temperature.

\section{REFERENCES}

1. P. W. Morgan, Macromolecules, 10, 1381 (1977).

2. W. C. Jackson, Jr. and H. F. Kuhfuss, J. Polym. Sci., Polym. Chem. Ed., 14, 2043 (1976).

3. J. Economy, R. S. Storm, V. I. Matkovich, S. G. Cottis, and B. E. Nowak, J. Polym. Sci., Polym. Chem. Ed., 14, 2207 (1976).

4. A. C. Griffin, T. R. Britt, and G. A. Campbell, Mol. Cryst. Liq. Cryst. (Lett.), 82, 145 (1982).

5. J. E. McIntyre and A. H. Milburn, Br. Polym. J., 13, 5 (1981).
6. T. Watanabe, S. Tasaka, and S. Miyata, Polym. Prepr. Jpn., 35, 2862 (1987).

7. S. M. Aharoni, Macromolecules, 21, 378 (1988).

8. J.-I. Jin, S. Antoun, C. Ober, and R. W. Lenz, Br. Polym. J., 12, 132 (1980).

9. T. Uryu and T. Kato, Macromolecules, 21, 378 (1988).

10. A. C. Griffin and S. J. Havens, J. Polym. Sci., Polym. Phys. Ed., 19, 951 (1981).

11. H. B. Donahoe, L. E. Benjamin, L. V. Fennoy, and D. Greff, J. Org. Chem., 26, 474 (1961).

12. C. L. Butler, Jr. and R. Adams, J. Am. Chem. Soc., 47, 2610 (1925).

13. B. Pawlewski, Ber., 35, 112 (1902).

14. C. Ober, R. W. Lenz, G. Galli, and E. Chiellini, Macromolecules, 16, 1034 (1983).

15. D. F. Ewing, Org. Magn. Resonance, 12, 499 (1979).

16. A. D. English, J. Polym. Sci., Polym. Phys., 24, 805 (1986).

17. S. Antoun, R. W. Lenz, and J.-I. Jin, J. Polym. Sci., Polym. Chem. Ed., 19, 1901 (1981); A. Blumstein, "Polymeric Liquid Crystals," Plenum Press, New York, N. Y., 1983, pp 22-23. 